\title{
Cross-border Childbirth Between Mainland China and Hong Kong: Social Pressures and Policy Outcomes
}

\author{
Bernard Yam, University of Technology, Sydney
}

\section{Introduction}

Hong Kong lies on the south coast of mainland China, bordering Guangdong province in the north and facing the South China Sea in the east, west and south. It had been a British colony for 156 years before it became a Special Administrative Region (SAR) of the People's Republic of China (PRC) on 1 July 1997. In spite of the outbreak of the Asian financial crisis that same year, Hong Kong's economic growth continued in the wake of the unprecedented developments in the Chinese economy. Accompanying the rapid industrialization and economic prosperity of many mainland provincial cities starting from the 1980s, more and more Hong Kong residents have been recruited to work in China. Many of these predominantly male workers eventually settled and married women from the mainland. In tandem, increased business activities between Chinese cities and Hong Kong have allowed mainland visitors to cross the border once mainland authorities endorsed their travelling arrangements. Visitors with an approved exit-entry permit for travelling to and from Hong Kong may stay for a period from 7 to 90 days. Apart from business travellers, there have been an increasing number of women from the mainland entering Hong Kong for the sole purpose of giving birth. Through the use of secondary sources, official statistics and government documents, this paper analyses the trend of cross-border childbirth in Hong Kong and the subsequent public outcry about overcrowded obstetric facilities that brought about changes to how and to whom obstetric services are provided.

PORTAL Journal of Multidisciplinary International Studies, vol. 8, no. 2, July 2011. Health and Borders Across Time and Cultures: China, India and the Indian Ocean Region Special Issue, guest edited by Beatriz Carrillo García and Devleena Ghosh. 


\section{The health care system in Hong Kong}

The Food and Health Bureau of the SAR is responsible for formulating policies and allocating resources for running Hong Kong's health services. The cornerstone of the government policy is that no one will be denied adequate medical care due to lack of means (Hong Kong Yearbook 2010). These policies and statutory functions are executed through the Department of Health. While a range of primary healthcare facilities are managed by this Department, all public hospitals and healthcare facilities (41 hospitals, 48 specialist out-patient clinics and 74 general out-patient clinics) are run by the Hospital Authority (HA), a statutory body established in 1990 to provide secondary, tertiary and specialized healthcare services. A total of 13 private hospitals, run independently from the government, also provide a wide range of medical services to healthcare consumers who can afford the costs. All private hospitals and five major public hospitals have been awarded full accreditation by international health care accreditation organizations such as the Australian Council on Healthcare Standards, the Joint Commission International and the Trent Accreditation Scheme (Hospital Authority 2010; Wong n. d.).

While meeting world-class standards of healthcare, fees for public hospitals and clinic services for Hong Kong residents are kept low; the public health system is subsidized by the government at about 95 percent of their full operating cost. Residents with financial difficulties are assisted through a fee waiver scheme, while people receiving welfare payments are exempted from payment (Hong Kong Yearbook 2010). Local residents are expected to pay an all-inclusive fee of HK\$100 (US\$13) per day as in-patients in an acute care hospital while non-local residents pay HK\$3,300 (US\$423) per day (Hospital Authority n. d.).

The benchmarks of health care in Hong Kong often exceed many advanced economies in the world, as indicated by various health care indicators. Common indicators used to measure maternal and newborn health are the neonatal mortality rate and maternal mortality ratio. Neonatal deaths are intricately linked with maternal deaths; when a mother dies during delivery, the foetus is also likely to die. These deaths can be prevented if there are adequate maternal health care services. Other indicators, such as infant mortality rates and the incidence of low birth-weight babies, also reflect the quality of maternal and infant health, but they are beyond the scope of this paper. 
The neonatal mortality rate (NMR) represents the number of deaths during the first 28 days of life for every thousand live births in a given year. It is a useful indicator of maternal and newborn health and care. According to the World Health Organization (WHO), neonatal deaths 'stem from poor maternal health, inadequate care during pregnancy, inappropriate management of complications during pregnancy and delivery, poor hygiene during delivery and the first critical hours after birth, and lack of newborn care' (WHO 2006: 2). As indicated in Table 1, NMR in Hong Kong has been under 2.0 per 1,000 live births since 2000 - this compares very favourably with developed countries like Australia, Canada, the UK and the USA. By contrast, NMR in mainland China was at least ten times higher than that of Hong Kong for the same period, reflecting an apparent lack of or access to good maternal and newborn health facilities.

\begin{tabular}{|c|c|c|c|c|}
\hline Country/Region & $\mathbf{1 9 9 5}^{\mathbf{1}}$ & $\mathbf{2 0 0 0}^{2}$ & $\mathbf{2 0 0 4}^{\mathbf{3}}$ & $\mathbf{2 0 0 8}^{\mathbf{4}}$ \\
\hline Hong Kong & 5 & 2 & 1 & $1.1^{\mathbf{5}}$ \\
\hline China & 35 & 21 & 18 & 11 \\
\hline Australia & 5 & 3 & 3 & 3 \\
\hline Canada & 5 & 4 & 3 & 4 \\
\hline UK & 5 & 4 & 3 & 3 \\
\hline USA & 5 & 5 & 4 & 4 \\
\hline World & 36 & 30 & 28 & 26 \\
\hline
\end{tabular}

Table 1: Neonatal mortality rate (per 1,000 live births). Note: NMRs for the year 1995 must be seen as discrete evaluations due to different methodologies used in the estimation.

Maternal mortality ratio (MMR) is the number of maternal deaths for every 100,000 live births during a set time-period. It is used to measure pregnancy-related deaths from direct or indirect causes. Direct obstetric deaths can be due to obstetric complications of the pregnancy or anaesthesia during delivery, while indirect obstetric deaths are those resulting from pre-existing conditions or diseases that developed during pregnancy (WHO 2010a). As seen in Table 2, maternal deaths in Hong Kong are consistently lower than the selected countries in the Western world, reflecting good quality care given to mothers and newborn babies. By contrast, the MMR in China is much higher, even though the rate has declined markedly over the past 20 years.

\footnotetext{
${ }^{1}$ Perinatal Mortality: A Listing of Available Information (WHO 1996: Table 1, 4, and Table 4, 16-22).

${ }^{2}$ Neonatal and Perinatal Mortality: Country, Regional and Global Estimates (WHO 2006: Table 6.1, 18 and Table A1.1, 29-34).

${ }^{3}$ Neonatal and Perinatal Mortality: Country, Regional and Global Estimates 2004 (WHO 2007: Table 2, 4 and Table 4, 6-14).

${ }^{4}$ World Health Statistics 2010 (WHO 2010b: Part 2, Table 1, 48-57) except Hong Kong.

${ }^{5}$ This is a 2007 figure adapted from Department of Health 2007/2008 Annual Report (2008: Tables on Health Status and Health Services 2007, Table A3).
} 


\begin{tabular}{|l|c|c|c|c|c|}
\hline Country/Region & $\mathbf{1 9 9 0}$ & $\mathbf{1 9 9 5}$ & $\mathbf{2 0 0 0}$ & $\mathbf{2 0 0 5}$ & $\mathbf{2 0 0 8}$ \\
\hline Hong Kong & 4.3 & 7.3 & 5.6 & 3.5 & 2.5 \\
\hline China & 110 & 82 & 60 & 44 & 38 \\
\hline Australia & 10 & 13 & 9 & 8 & 8 \\
\hline Canada & 6 & 7 & 7 & 12 & 12 \\
\hline UK & 10 & 10 & 12 & 13 & 12 \\
\hline USA & 12 & 11 & 14 & 24 & 24 \\
\hline World & 400 & 370 & 340 & 290 & 260 \\
\hline
\end{tabular}

Table 2: Maternal mortality ratio (per 100,000 live births) ${ }^{6}$

Despite the differences and limitations in reporting and classification amongst different countries, empirical data routinely collected by developed countries can be used for international comparison. These two widely used standardized indicators (NMR \& MMR) confirm the enviable record of obstetric and newborn care as well as the efficiency of general and public health services in Hong Kong.

\section{Giving birth in Hong Kong}

It is not uncommon to have non-permanent residents giving birth in Hong Kong in the well-equipped hospitals staffed by qualified health care providers. This could arise as a result of emergencies such as premature labour or an expatriate's planned childbirth. Such situations are usually handled well as long as the number is manageable and the hospital expenses are covered. From the $1^{\text {st }}$ of September 2005 the standard obstetric package in a public hospital for non-local residents was set at HK\$20,000 (US\$2,564), and included all the services in the first three days of hospitalization; special services or extra hospital stay would attract additional charges. Women who prefer to have their own obstetrician in a private hospital are expected to pay more. Many local expectant women opt for this option as well. Table 3 shows a breakdown of the number of live births by eligible persons (persons who have permanent residency in Hong Kong) and non-eligible persons (non-permanent residents of Hong Kong) in public and private hospitals. Although there is no further breakdown in the various categories of noneligible persons, there is adequate evidence to support the assertion that there has been a significant increase in demand in obstetric service by non-permanent residents. Between 2004 and 2005, the number of live births in public hospitals for this group of women

\footnotetext{
${ }^{6}$ Maternal mortality rates for Hong Kong, 1990-2005, were adapted from Department of Health 2007/2008 Annual Report (Department of Health 2008: Table A3). Maternal mortality rate for 2008 was adapted from Hong Kong Yearbook 2008 (2008: 154). Trends in Maternal Mortality for all other countries and the world, 1990 to 2008, derive from estimates developed by WHO, UNICEFF, UNFPA and the World Bank (WHO 2010a: Annex 3, 28-31, and Appendix 7, 39).
} 
increased by 25 percent and by 137 percent in private hospitals. In 2005 alone, one in three newborns in Hong Kong were delivered by non-resident women.

\begin{tabular}{|c|ccc|ccc|}
\hline Year & \multicolumn{3}{|c|}{ Public Hospitals } & \multicolumn{3}{c|}{ Private Hospitals } \\
& NEP* & EP* & Total & NEP* & EP* & Total \\
& $\mathrm{N}(\%)$ & $\mathrm{N}(\%)$ & $\mathrm{N}(\%)$ & $\mathrm{N}(\%)$ & $\mathrm{N}(\%)$ & $\mathrm{N}(\%)$ \\
\hline 2004 & 11,116 & 26,552 & 37,668 & 2,377 & 9,765 & 12,142 \\
& $(30 \%)$ & $(70 \%)$ & $(100 \%)$ & $(20 \%)$ & $(80 \%)$ & $(100 \%)$ \\
\hline 2005 & 13,917 & 27,342 & 41,259 & 5,639 & 10,201 & 15,840 \\
& $(34 \%)$ & $(66 \%)$ & $(100 \%)$ & $(36 \%)$ & $(64 \%)$ & $(100 \%)$ \\
\hline \% increase & $25 \%$ & $3 \%$ & $10 \%$ & $137 \%$ & $5 \%$ & $31 \%$ \\
\hline
\end{tabular}

Table 3: Live births in public and private hospitals in Hong Kong, 2004-2005. * NEP = Noneligible persons (e.g. foreign passport holders, People's Republic of China passport holders or illegal entrants from mainland China. According to Au Yeung (2006: 43), the latter group of passport holders constitute the majority of NEP deliveries in public hospitals); $* \mathrm{EP}=$ Eligible persons (local residents or residents with the right of abode in Hong Kong).

While detailed information from private hospitals can be difficult to access, it is common knowledge that many local and expatriate pregnant women prefer the comfort and services of private hospitals while those from mainland China will settle for the less expensive public hospitals to have their delivery. As seen from Table 4 the percentage of live births born to mainland women increased from 10.2 percent in 1995 to 45.4 percent in 2009 .

\begin{tabular}{|c|c|c|c|}
\hline Year & $\begin{array}{c}\text { Total Live } \\
\text { Births }\end{array}$ & $\begin{array}{c}\text { No. of Live Births Born to } \\
\text { Mainland Women }\end{array}$ & $\begin{array}{c}\text { \%o of Total } \\
\text { Births }\end{array}$ \\
\hline 1995 & 68,637 & $7,025^{1}$ & $10.2 \%$ \\
\hline 1996 & 63,291 & $6,494^{1}$ & $10.3 \%$ \\
\hline 1997 & 59,250 & $5,830^{1}$ & $9.8 \%$ \\
\hline 1998 & 52,977 & $6,015^{1}$ & $11.4 \%$ \\
\hline 1999 & 51,281 & $7,081^{1}$ & $13.8 \%$ \\
\hline 2000 & 54,134 & $8,173^{2}$ & $15.1 \%$ \\
\hline 2001 & 48,219 & $7,810^{2}$ & $16.2 \%$ \\
\hline 2002 & 48,209 & $8,506^{2}$ & $17.6 \%$ \\
\hline 2003 & 46,965 & $10,128^{2}$ & $21.6 \%$ \\
\hline 2004 & 49,796 & $13,209^{2}$ & $26.5 \%$ \\
\hline 2005 & 57,098 & $19,538^{2}$ & $34.2 \%$ \\
\hline 2006 & 65,626 & $26,132^{2}$ & $39.8 \%$ \\
\hline 2007 & 70,875 & $27,574^{2}$ & $38.9 \%$ \\
\hline 2008 & 78,822 & $33,565^{2}$ & $42.6 \%$ \\
\hline 2009 & 82,095 & $37,253^{2}$ & $45.4 \%$ \\
\hline
\end{tabular}

Table 4: Number of live births born to mainland women in Hong Kong, 1995-2009.

${ }^{1}$ Demographic Trends in Hong Kong 1981-2001 (Census and Statistics Department 2002: Table 3.9, 35). ${ }^{2}$ Hong Kong Population Projections 2010-2039 (Census and Statistics Department 2010: Table 4, 32).

The birth rate in Hong Kong has continued to drop since the 1990s and it reached a trough in 2003 (Table 4). Obstetric units in some public hospitals were either closed 
down permanently or amalgamated with other units, resulting in a reduction in the number of obstetric beds. Similarly, three out of four midwifery schools gradually suspended intake of students from 1999 and the number of new trainee specialist obstetrician positions in public hospitals were at the lowest in 2004. All these factors contributed to the crisis in obstetric services and manpower shortage that erupted in 2006 (Au Yeung 2006).

\section{The obstetric crisis of 2006}

In 2001, after a tortuous political and legal process the Hong Kong SAR government granted residency rights to babies born in Hong Kong to Chinese parents (M. Cheng 2007; Leung 2009). These residency rights include permanent residency, full access to free public education, subsidized healthcare and social welfare services (M. Cheng 2007). In 2007 the Census and Statistics Department conducted a population projection survey on babies born in Hong Kong to mainland women. It was found that for babies born to parents without the right of abode in Hong Kong, 91 percent of parents planned to bring their babies back to China; 29 percent of these babies were expected to return to Hong Kong at or before age 3 and 49 percent at or before their sixth birthday, to commence pre-primary and primary school education respectively. For babies born to mainland women whose spouses are Hong Kong permanent residents, 65 percent would stay in Hong Kong. Although the remaining 35 percent would return to China, 72 percent of these babies would eventually return to Hong Kong at or before the age of 3 , and 84 percent at or before 6 years of age (Legislative Council Press Release 2008b). These results confirm the common belief that these mainland women crossed the border to give birth, not only because of the superior health care facilities in the territory but also for other entitlements provided by the government to its permanent residents (Yam \& Au 2004).

Since Hong Kong became part of the PRC in 1997, mainland residents are now allowed to visit the territory with less travel restrictions. Travel agencies on both sides of the border have mushroomed, including those offering maternity packages to mainland expectant women that include transport, accommodation and assistance to emergency room when in labour (M. Cheng 2007). As noted in Table 4, the number of babies born to mainland women in Hong Kong increased dramatically from 5,830 in 1997 to 26,132 in 2006, an exponential growth of 348 percent in ten years. Coinciding with the closure 
of maternity beds and the lack of qualified midwives and specialist obstetricians, such a staggering influx of unplanned admissions not only lead to overcrowding of emergency departments and maternity wards, it also flows onto other hospital units such as neonatal intensive care units and operating rooms.

It has been reported that many overstay visitors and illegal entrants from China are less likely to seek antenatal care until birth is imminent for fear of repatriation (Yam \& $\mathrm{Au}$ 2004). This is especially true if the parents want to evade China's one-child policy (Leung 2009). These women usually turn up in the emergency department in an advanced stage of labour (Leung 2009), and usually at nighttime to avoid being identified by law enforcement personnel. Moir (1998) has also reported that these pregnant women are more than three times as likely as local women to give birth before arrival at hospital. With no antenatal record or information on past medical history, these women place themselves and their unborn child at risk of complicated labour or undiagnosed foetal anomalies (Leung 2009). Similarly, staff risk contacting unidentified communicable diseases.

In a letter addressed to the Panel on Health Services of the Legislative Council, the Secretary for Health, Welfare and Food Bureau acknowledged that about 85 percent of mainland pregnant women were admitted through the Emergency Department, and over 80 percent had little antenatal care or were unable to produce satisfactory evidence of such care. Furthermore, between 2005 and 2006 the rate of defaulted medical fees by pregnant mainland women was 15 percent (P. Cheng 2007). During the 2004-2005 financial year, 1,670 mainland women failed to pay HK\$12.64 million (US\$1.63m) in hospital fees. By 2005-2006, 2,138 women defaulted HK\$28.58m (US\$3.68m) in medical fees (M. Cheng 2007), an increase of 126 percent in just twelve months.

The exploitation of medical resources by pregnant mainland women, the overcrowding of obstetric services and the lack of public accountability of the SAR government and the Hospital Authority (HA) sparked a public outcry and intense media coverage in 2006. On 19 November 2006, a group of 50 local pregnant women took to the streets and protested outside the government headquarters to complain about the shortage of maternity services and the decreased standard of care, the failure of the government and the HA to safeguard taxpayers' money and the lack of planning to curb the influx of mainland expectant mothers giving birth in Hong Kong. As a result of heated 
discussions amongst the media and the public earned this public health issue the number one spot in the '10 Major Health News' contest held by Radio Television Hong Kong, the government-funded broadcaster (Lee 2007).

On 16 January 2007 the Government announced new arrangements for obstetric services aimed at ensuring that local expectant women would receive proper and priority treatment. A central booking system to manage all antenatal bookings was implemented by the HA on the $1^{\text {st }}$ of February 2007. It would reserve sufficient places for local pregnant women and if extra places were available, the HA would accept bookings from non-local expectant women. Once service capacity is reached, bookings from non-local pregnant women cannot be made. Similarly, all private hospitals offering obstetric services were to provide the same booking procedure. In tandem, a new revamped obstetric package was introduced, consisting of one antenatal visit, vaginal or operative delivery and three days of in-patient services. While local women continue to pay the standard fees, non-local women must pay HK\$39,000 (US\$5,000) in full at the time of booking. Women without a prior booking must pay $\mathrm{HK} \$ 48,000$ (US\$6,154) before they can be attended by healthcare personnel. Border controls have also been stepped up; women who are pregnant beyond 28 weeks' gestation are denied entry unless they can provide documentary evidence showing that they have made a booking with a public or private hospital. Additional training for health care providers has also been expanded (Government Information Centre Press Release 2007).

In a review of this new obstetric package, the HA conducted an audit based on the number of births in public hospitals. Between February and December 2007 the number of deliveries by local women in public hospitals increased by 8.6 percent from the same period in 2006; representing a total of 28,062 births (Table 5). Deliveries by non-local pregnant women decreased by 29.4 percent to 7,711 in the corresponding period. Since non-local pregnant women were only allowed to book obstetric services at public hospitals when service capacity was available, the booking system was successful in meeting the needs of local women. In order to quell non-local expectant women from seeking emergency hospital admissions through Emergency Departments shortly before labour, a higher service charge was also set. This strategy proved effective; from February to December 2007, out of 7,771 births by non-local women, only 1,171 (15.1 percent) sought emergency hospital admissions through the Emergency Departments. In 
the same period in 2006, the figure was 88.8 percent. Compliance with the booking system amongst non-local expectant mothers also increased significantly, an increase of 229 percent since the booking started. The majority of these women had attended an antenatal visit; therefore the risk of obstetric complications and unrecognized congenital anomalies of the foetus would have been detected earlier. This not only benefited the women and the unborn babies but also eased the workload of health care providers. With an up-to-date central booking system mapping the likely utilization pattern of public obstetric services, better service planning was facilitated to meet the needs of expectant mothers and staff allocation.

\begin{tabular}{|c|c|ccc|c|}
\hline Year & \multicolumn{3}{|c|}{ By Eligible } & \multicolumn{3}{|c|}{ By Non-Eligible Persons (NEP) } & Total \\
& Persons (EP) & Booked & $\begin{array}{c}\text { Non-booked } \\
\text { cases }\end{array}$ & cases & NEP \\
subtotal & \\
\hline $\begin{array}{c}2006 \\
\text { (Feb. }- \text { Dec.) }\end{array}$ & 25,834 & 2,007 & 8,997 & 11,004 & 36,838 \\
\hline $\begin{array}{c}2007 \\
\text { (Feb. }- \text { Dec. })\end{array}$ & 28,062 & 6,600 & 1,171 & 7,771 & 35,833 \\
\hline$\%$ change & $+8.6 \%$ & $+228.8 \%$ & $-87 \%$ & $-29.4 \%$ & $-2.7 \%$ \\
\hline
\end{tabular}

Table 5: Review of the obstetric service package based on the number of births in public hospitals. Source: Legislative Council paper (2008a).

With 6,600 bookings between February and December 2007 in public hospitals alone, the HA secured a total of HK\$257.4m (US\$33m) in advanced payments. Unless there were complications requiring an extended hospital stay, this system helped limit the amount of unpaid hospital fees as well as the costs of debt recovery. Under the new scheme the bill settlement rate for booked and non-booked cases was 99.8 percent and 61.8 percent respectively (Legislative Council paper 2008b). According to the same Legislative Council paper, in the period from February to December 2007, the total number of booking certificates issued to non-local expectant women by public and private hospital was 11,084 and 24,551 respectively. This translated to HK\$432.3m (US\$55.4m) for public hospitals and HK\$957.5m (US\$122.8m) for private hospitals with maternity facilities.

With China's phenomenal economic development, more and more Chinese parents with the financial means have the choice of selecting in which overseas country they want their baby to be delivered. With a similar culture and short travel time, giving birth in well-equipped hospitals in Hong Kong appears to be a popular choice. The advanced payment has not deterred their decision. As noted in Table 6, the percentage of babies 
born to parents who are not permanent residents in Hong Kong increased from 68.2 percent when the new obstetric package was introduced in 2007, to almost 80 percent in 2009.

\begin{tabular}{|c|c|c|c|}
\hline Year & $\begin{array}{c}\text { Number of Live } \\
\text { Births Born to } \\
\text { Mainland Women }\end{array}$ & $\begin{array}{c}\text { Number of Live Births Whose Fathers Are Not } \\
\text { Hong Kong Permanent Residents }\end{array}$ \\
\hline 2001 & 7,810 & 620 & $7.9 \%$ \\
\hline 2002 & 8,506 & 1,250 & $14.7 \%$ \\
\hline 2003 & 10,128 & 2,070 & $20.4 \%$ \\
\hline 2004 & 13,209 & 4,102 & $31.1 \%$ \\
\hline 2005 & 19,538 & 9,273 & $47.5 \%$ \\
\hline 2006 & 26,132 & 16,044 & $61.4 \%$ \\
\hline 2007 & 27,574 & 18,816 & $68.2 \%$ \\
\hline 2008 & 33,565 & 25,269 & $75.3 \%$ \\
\hline 2009 & 37,253 & 29,766 & $79.9 \%$ \\
\hline
\end{tabular}

Table 6: Number of live births born to mainland Chinese parents in Hong Kong, 2001-2009. Source: Hong Kong Population Projections 2010-2039 (Census and Statistics Department 2010: Table 4, 32).

Certain predictable phenomena will happen if this growth trend continues. Apart from the tourist dollars, there will be a steady clientele for private hospitals and obstetricians in private practice and more training places and job opportunities for midwives, neonatal intensive care nurses and trainee specialist obstetricians. To go beyond these obvious predictions can be problematic as there is no precedent to go by. As indicated by the population projections survey noted earlier, these babies are likely to be brought back to Hong Kong for primary and secondary education. There will be a demand for teachers, as well as an urgent need to improve their language ability. Teachers will need to learn Mandarin or putonghua, the official language of the PRC, in order to communicate effectively with the children and their parents or carers. The impact of the arrival of these children on Hong Kong's local community should not be underestimated. Additional demand means social services such as housing, education, health care, welfare and employment services must be put in place. In view of the many uncertainties and the absence of historical trends for reference, it is difficult to project more precisely on government planning except to monitor the situation closely and carry out population projections regularly. On a more positive note, however, this population 'explosion' in a low birth rate society like that of Hong Kong could become an asset for the ageing population if these children remain in the territory. They may even contribute to the prosperity of Hong Kong. Such optimistic predictions remain to be seen in the years ahead. 


\section{Limitations of this paper}

As a research tool, secondary data analysis uses information that was either collected by agencies such as governments and research institutions or for some other purposes than the one being examined. Researchers using this research method can only work with the data that exist, not what they would like to have (Stewart \& Kamins 1993; Boslaugh 2007). Population statistics used in this paper come from data routinely collected by the government under the supervision of qualified statisticians. These data are often forwarded to global organizations like the World Bank and the WHO for compilation of population reports. Despite certain limitations on data collection methods, this information is reliable and is frequently used in cross-national comparisons. When researchers want to examine specific local data, information can be difficult to obtain because these information is not always collected. For example, the sex ratio of babies delivered by local and mainland mothers at the time of birth is not published in the reports. Moreover, even if the information is available, the cost of data extraction from various databases could be prohibitively expensive.

Another example of gaps in the data is highlighted in Table 5, where government departments provided data related to questions raised by members of the Legislative Council. In its response to the review of the obstetric package, the government released information on the number of births by local and non-local women in public hospitals collected 11 months before and after its implementation. However, since private hospitals have no legal obligation to provide more than the basic information, there is a gap in the picture. Had the legislators followed up on their earlier questions in subsequent Council meetings, the efficacy of this policy could have been further established, at least in the public hospital system. Such an approach would make the government more accountable to its people.

The major weakness in the use of secondary data is the fact that they cannot reveal personal values, beliefs or reasons behind the actions of individual actors. Controversial topics such as baby gender selection, selective abortion and social factors influencing the choices of expectant women are not available from these data sources. If the attending obstetricians are not interested in collecting data outside their scope of medical practice, this information is not collected. Even if this information exists, the rigour of its collection is unknown and hence it is inappropriate to generalise beyond the 
primary source. Furthermore, patient records are confidential documents that can only be released with the written authorization of the women. All these important social issues are relevant to researchers interested in bridging this gap. This paper can only complement further qualitative research activity using primary data collection such as in-depth interviews.

\section{Conclusion}

This paper demonstrates the use and validity of secondary data in trend analysis on an important social issue. It documents the rising trend on cross-border childbirth between mainland China and Hong Kong, the enormous strain this poses on local obstetric services, as well as policy changes implemented by the SAR government to rectify the situation. Apart from giving local expectant mothers priority of care, the new policy also brings more business opportunities for private hospitals and obstetricians as well as job opportunities for health care providers, from mainland Chinese seeking better healthcare services. The residency and various entitlements (better education and access to better employment opportunities) available to those born in Hong Kong, are also envisioned as a means to keep these new citizens in Hong Kong. This could add new impetus to the economic growth of Hong Kong and alleviate some of the issues posed by the ageing of Hong Kong's population - the ultimate gift those newborns can give back to their place of birth. Further research to bridge the gaps identified in this paper should be encouraged and supported by governments and social research institutions.

\section{Reference List}

Au Yeung, S. 2006, 'Impact of Non-Eligible Person Deliveries in Obstetric Service in Hong Kong,' Hong Kong Journal of Gynaecology, Obstetrics \& Midwifery, vol. 6, no. 1: 41-44.

Boslaugh, S. 2007, Secondary Data Sources for Public Health: A Practical Guide. Cambridge University Press, Cambridge.

Census and Statistics Department, Hong Kong Special Administrative Region 2002, Demographic Trends in Hong Kong 1981-2001. Online available:

http://www.censtatd.gov.hk/products_and_services/products/publications/statistical_report/populat ion_and_vital_events/index_cd_B112001701_dt_latest.jsp [Accessed 9 November 2010]. 2010, $\bar{H}$ ong Kong Population Projections 2010-2039. Online available: http://www.censtatd.gov.hk/products_and_services/products/publications/statistical_report/populat ion_and_vital_events/index_cd_B112001504_dt_latest.jsp [Accessed 9 November 2010].

Cheng, M. $200 \overline{7}$, 'Hong Kong Attempts to Reduce Influx of Pregnant Chinese,' Lancet, vol. 369, no. 9566: 981-982.

Cheng, P. 2007, Impact of Use of Obstetric Services by Mainland Women on Public Hospital Resources. 9 January. Online, available: http://www.legco.gov.hk/yr06-

07/english/panels/hs/papers/hs0108cb2-833-1-e.pdf [Accessed 12 November 2010].

Department of Health, The Government of the Hong Kong Special Administrative Region 2008, Department of Health 2007/2008 Annual Report. Tables on Health Status and Health Services 
2007. Online, available:

http://www.dh.gov.hk/english/pub_rec/pub_rec_lpoi/pub_rec_lpoi_thshs_2007.html [Accessed 2 November 2010].

Government Information Centre 2007, Press Releases. New Measures on Obstetric Services and Immigration Control Announced. 16 January. Online, available: http://www.info.gov.hk/gia/general/200701/16/P200701160184.htm [Accessed 12 November 2010].

Hong Kong Yearbook 2008 2008, Online, available: http://www.yearbook.gov.hk/2008/en/index.html [Accessed 2 November 2010].

Hong Kong Yearbook 2010 2010, Online, available: http://www.yearbook.gov.hk/2010/en/index.html [Accessed 23 September 2011].

Hospital Authority 2010, Press Release. Two More Public Hospitals Awarded International Accreditation. 4 November. Online, available: http://www.ha.org.hk/haho/ho/pad/101104Eng.pdf [Accessed 15 November 2010]. n. d., Fees and charges. Online, available: http://www.ha.org.hk/visitor/ha_visitor_index.asp?Parent_ID $=10044 \&$ Content_ID=10045\&Ver= HTML [Accessed 23 September 2011].

Legislative Council, HKSAR 2008a, Legislative Council Panel on Health Services. Review of the Obstetric Service Package Charge for Non-Eligible Persons. 18 February. Online, available: http://www.legco.gov.hk/yr07-08/english/panels/hs/papers/hs0218cb2-1050-3-e.pdf [Assessed 12 November 2010]. 2008b, Press Releases. LCQ17: Babies Born in Hong Kong to Mainland Women. 9 April. Online, available: http://www.info.gov.hk/gia/general/200804/09/P200804090257.htm [Accessed 12 November 2010].

Lee, K. 2007, Motions: Non-Local Pregnant Women Giving Birth in Hong Kong. Online, available: http://www.leekoklong.org.hk/e_index.htm [Accessed 12 November 2010].

Leung, W. 2009, 'Social Obstetrics: Non-Local Expectant Mothers Delivering Babies in Hong Kong' Hong Kong Medical Diary, vol. 14, no. 3: 13-14.

Moir, J. 1998, 'Illegal Immigrant Mothers at Risk from Lack of Check-ups.' South China Morning Post, 22 June: 3 .

Stewart, D. W. \& Kamins, M. A. 1993, Secondary Research: Information Sources and Methods. $2^{\text {nd }}$ ed., Sage, Newbury Park.

Wong, W. n. d., Trent and JCI Hospital Accreditation. What For? And Why Both? Online, available: http://www.wongsworld.org/dad_web_presence/Trent\%20and\%20JCI\%20hospital\%20accreditatio n\%20-\%20What\%20for\%20and\%20why\%20both.pdf [Assessed 15 November 2010].

World Health Organization 1996, Perinatal Mortality: A Listing of Available Information. WHO, Geneva. 2006, Neonatal and Perinatal Mortality: Country, Regional and Global Estimates. WHO, Geneva. 2007, Neonatal and Perinatal Mortality: Country, Regional and Global Estimates 2004. WHO, Geneva. 2010a, Trends in Maternal Mortality: 1990 to 2008. Estimates Developed by WHO, UNICEFF, UNFPA and the World Bank, WHO, Geneva. 2010b, World Health Statistics 2010, WHO, Geneva.

Yam, B. \& Au, S. 2004, 'Comparison of the Experiences of Having a Sick Baby in a Neonatal Intensive Care Unit Among Mothers With and Without the Right of Abode in Hong Kong,' Journal of Clinical Nursing, vol. 13, no. 1: 118-119. 